TEJIDO HISTÓRICO DE LA CASACIÓN EN COLOMBIA A PARTIR DE SU ORIGEN A LOS TIEMPOS ACTUALES

RICARDO MARTÍNEZ QUINTERO

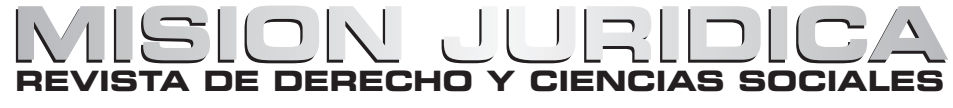





\title{
TEJIDO HISTÓRICO DE LA CASACIÓN EN COLOMBIA A PARTIR DE SU ORIGEN A LOS TIEMPOS ACTUALES *
}

\author{
HISTORIC FABRIC OF THE APPEAL SYSTEM \\ IN COLOMBIA FROM ITS ORIGIN \\ TO THE PRESENT TIME \\ TECIDO HISTÓRICO DA CASSAÇÃO \\ NA COLOMBia \\ DESDE SUA ORIGEM ATÉ HOJE.
}

\author{
RICARDO MARTÍNEZ QUINTERO** \\ ricardo.martinez@unicolmayor.edu.co \\ Universidad Colegio Mayor de Cundinamarca \\ Recibido par académico: 4-05-2011. Aceptado: 17-08-2011
}

\section{RESUMEN}

El trabajo que se deja a disposición de los lectores resulta ser un ejercicio del curso precedente de artículos publicados en números antelares, de la línea histórica que acompaña la temática que se expresa en los siguientes puntos: Mito y normatividad: hermenéutica hacia una cultura política de identidad y unidad nacional, constitucionalismo colombiano, frente al recurso de casación declaratoria de nulidades de ciertos fallos, casación moderna: trascendencia histórica en la defensa o protección de las garantías fundamentales, la Constitución de 1886 y la expresión constitucional del término casación, punto de partida del recurso como secuela del pasado, donde se combina lo histórico con lo jurídico y lo anecdótico en expresiones traídas en los propios textos.

\section{palabras claves}

Hermenéutica, unidad nacional, constitucionalismo colombiano, recurso de casación, garantías fundamentales, función nomofiláctica.

\section{ABSTRACT}

The work makes available to readers, it is an exercise in the previous year of articles published in antelares numbers, the story line that accompanies the theme expressed in the following: Myth and regulations: hermeneutics to a political culture identity and national unity, constitutionalism Colombian appeal against the declaration of nullity of certain faults, modern appeal, historical significance in the defense or the protection of fundamental guarantees, the constitution of 1886 and the appeal of the term

\footnotetext{
* Este artículo es producto de la investigación adelantada por el autor para su tesis de maestría en filosofía latinoamericana, titulado "La influencia del pensamiento colonial en parte de la casación penal de la Corte Suprema de Justicia", realizada en la Universidad Santo Tomás de Bogotá.

* Abogado egresado de la Universidad Externado de Colombia. Magíster en Derecho Penal y Ciencias Criminológicas de la Universidad Externado de Colombia y en Derecho Procesal de la Universidad del Rosario. Magíster en Filosofía Latinoamericana de la Universidad Santo Tomás. Decano de la Facultad de Derecho de la Universidad Colegio Mayor de Cundinamarca.
} 
constitutional expression, point departure in the wake of last resort, combining the historical and legal and anecdotal brought expressions in the texts themselves.

\section{KEY WORDS}

Hermeneutics, national unity, constitutionalism Colombian appeal fundamental guarantees.

\section{SUMÁRIO}

O trabalho colocado à disposição dos leitores é um exercício que resulta do curso anterior de artigos publicados em números precedentes, da linha histórica que acompanha a temática exprimida nos seguintes pontos: mito e normatividade: hermenêutica para uma cultura política da identidade e da unidade nacional, constitucionalismo colombiano, à frente do recurso de cassação declaratória de nulidades de certas sentenças, cassação moderna: importância histórica na defesa ou proteção das garantias fundamentais, a Constituição de 1886 e a expressão constitucional do termo expressão constitucional, ponto de partida do recurso como sequela do passado, onde se combina o histórico com o jurídico e o anedótico nas expressões trazidas dos próprios textos.

\section{PALAVRAS-CHAVE}

Hermenêutica, unidade nacional, constitucionalismo colombiano, recurso de cassação, garantias fundamentais, função nomofilática.

\section{INTRODUCcióN}

El manejo de los institutos sin la previa consulta de sus orígenes puede ser una si no la principal de las causas para que su naturaleza se vaya desdibujando dando paso a su abuso.

Las reformas constitucionales en este sentido no se pueden limitar a la mera aparente objetividad del establecimiento o restablecimiento de ciertos órdenes. Por el contrario aquellas contienen una información codificada, no por numeración, de la que desprenden las intenciones de sus autores y con ellas el dato de suficiencia para conocer el porqué de nuestra realidad.

Para el caso fue lo que impulsó esta porción de un extenso trabajo en el que se pone de manifiesto la injerencia del pensamiento de los conquistadores en los destinos de Latinoamérica en especial en Colombia. País en el que sutilmente con voces de libertad y emancipación se vino consolidando el principio de mera legalidad como único instrumento capaz de reglar la administración de justicia sin las advertencias de los intelectuales imparciales del derecho, ni de algunos historiadores, sobre lo que al interior de esta figura se vertía como elemento frenador de los avances de la ciencia jurídica.

En el tema de la casación la prevalencia de la forma sobre el fondo, el de la técnica sobre la sustancia, el de la procedencia y las causales sobre los fines. Situación que viene a descubrirse con notoriedad manifiesta a partir del texto constitucional de 1991 ante los ojos de quienes por largo tiempo a la usanza de lo previsto en la Carta 
de 1886 limitaron el recurso extraordinario de conformidad con las restricciones de una ideología poco progresista y por ende transgresora de muchos de los que hoy se coligen como derechos fundamentales.

Por las indicadas razones el lector encontrará los referentes necesarios para dejar volar su pensamiento en reflexiones extraídas de la propia historia y de esta forma plantearse el futuro relacionado con la materia, que si bien ha obtenido avances, innegable que de la marcha falta bastante. Para entre otras cosas lograr la consolidación de un Estado de derecho más justo, más garante, más humano.

\section{PROBLEMA DE INVESTIGACIÓN}

Dentro de ese nuevo panorama que ofrece la casación al interior del sistema jurídico trazado por la Carta de 1991 resulta indispensable conocer si realmente el recurso extraordinario superó los límites que le impusiera el viejo derecho proveniente de la conquista, la colonia, la emancipación y la república teorizada en la Constitución de 1886.

Ejercicio de necesaria práctica, entre otros los estudiosos del derecho, los historiadores, los sociólogos, los filósofos y todos aquellos que por convicción dejen ingresar en el patrimonio de su intelectualidad nuevos insumos de observación a fin de que se pueda elaborar una novísima arquitectura del derecho en Colombia a partir del concepto antropocéntrico que no legalista.

Desde esta perspectiva los elementos que informaron legalmente un recurso casi intocable por una excesiva técnica y declaratoria de deidad jurídica ahora son sustituidos por otros de mayor vocación filosófica a través de una nueva hermenéutica basada en la tópica, la nueva lógica y sobre todo la teoría del discurso moral práctico desalojado del cuadro de acción en el régimen legalista de la Constitución de 1886. Los fines de la casación son el fundamento filosófico del recurso.

Además resulta imperioso en esta época destacar aquellas respecto de las cuales, casi en sentido contrario a la naturaleza de las conquistas del derecho se actuó más con sentido político que jurídico. Por decir lo menos, interesante hacer un alto en el camino para determinar reflexivamente el acierto o la incorrección de haberse considerado el recurso extraordinario apenas como una reacción frente a determinados delitos que por su gravedad previno el legislador de entonces la aplicación de la pena de muerte. De tal suerte que, abolida esta, condujo a la también expulsión del sistema jurídico el recurso.

\section{METODOLOGÍA}

Enrostrando la problemática planteada, el presente ejercicio puesto a consideración de los lectores hace un rastreo histórico fundamentado en los textos constitucionales en Colombia a partir de la llamada emancipación hasta nuestros días, con la intención de descubrir la real injerencia del pensamiento individual del Libertador en el manejo legislativo del recurso extraordinario de casación a través de los tiempos. Expresión de la sombra dejada por la conquista, la colonia y la independencia hasta el año de 1991 en el que, al parecer, en medio de las dificultades provocadas por una cultura de mera legalidad empezó a tener algún sentido epistemológico un buen número de consignas vertidas en el movimiento revolucionario de Francia en 1789. 
Un marco descriptivo y de reseña histórica en el que se adveran sin posibilidad de ocultamiento los permanentes sucesos sangrientos por los que ha atravesado la patria en medio de las luchas partidistas, la polarización, la endogamia y distintas fenomenologías que con el título de lo general han terminado por poner de presente más bien la apropiación de lo público por los particulares.

En esta tónica intentar llegar al lector para que extraiga sus propias conclusiones en torno a la evolución histórica de algunas de nuestras instituciones, sus protagonistas y sobre todo poder advertir la vecindad en nuestras vidas de tantos hechos derivados del pasado.

\section{CONTEXTO HISTÓRICO DE LA CASACIÓN EN COLOMBIA DESDE SUS GÉNESIS HASTA HOY}

\section{A. MITO Y NORMATIVIDAD: HERMÉNEUTICA HACIA UNA CULTURA POLÍTICA DE IDENTIDAD Y UNIDAD NACIONAL}

El evidente apego a compartidas actitudes denotativas de las personalidades de los protagonistas de la historia nuestra, como la de la defensa de los intereses personales, va desde Cristóbal Colón, hasta los bautizados por los estudiosos, como los emancipadores, Bolívar y Santander. Pauta o común denominador en el decurso de los sucesos que llegaron a la aparente liberación de Colombia del yugo conquistador escenificado en la colonia y que pervive en la época actual.

Premisa que permite colegir por qué aún vivimos contagiados con los mismos males que otrora sirvieron de fundamento para plantear acomodaticiamente políticas en apariencia tendientes a alcanzar las metas de identidad y unidad nacional. Fenómeno del que nada escapó, entre ello el instrumento procesal de la administración de justicia que debió contribuir con alguna eficacia en la arquitectura de una verdadera nación con unidad de propósitos, lo que teóricamente hubiera frenado tantos desmanes provocados por el regionalismo, el caudillismo, la exclusión social, la endogamia, la plutocracia.

Así lo fermentado en la Colonia permanece mostrando un pasaje de sombra sin luz propia que clarifique la razón de ser de un Estado. Asunto que en este trabajo permitirá ver un concepto de derecho netamente legalista, dentro del que fluye el factor social. Esto es un estudio social del derecho.

Por lo anotado, la metodología descriptiva utilizada en este ejercicio demostrará la influencia de la colonia en parte de la jurisprudencia de la Sala Penal de la Corte Suprema de Justicia. El relato de los más significativos hechos con que ha tenido que transitar la casación desde su creación legal -en una historia de mitos frustrados o elididos-. Calificación que doy en términos de cultura, de acuerdo con Cassirer, en el sentido de ser el mito uno de los elementos de toda cultura junto con la religión, el lenguaje, la ciencia y el arte.

Por suerte que al abordar la temática desde el punto de vista netamente normativo, la radiografía de la historia trasluce el efecto de lo político autocrático, sobre lo jurídico. Hecho delator de algunas de las consecuencias que ello ha suscitado en las distintas generaciones en Colombia que a más de ser reconocidas en su diversidad étnica visible en el indigenismo, la negritud, el mestizaje, la visión de los gobernantes, 
debió contar mejor en la reivindicación de la categoría de "colombianos", con una memoria excelsa de las experiencias, para recibir con decoro las moralejas y así haber comprendido y entendido la independencia, como paso previo a la libertad, frente al conquistador y luego lo mismo, frente a los manipuladores de lo económico. Pero ello no aconteció, de ahí la repetición de la historia, con distintos atuendos, pero con idéntica actitud promotora de la preservación del pasado.

Convertidos Bolívar y Santander en mitos por los historiadores, el primero como guerrero de la libertad, anhelante de independencia, sin galanteo por la democracia, el segundo es reconocido fundador de los gobiernos civiles de Colombia; ello los llevó a una enconada disputa cuyos elementos se trasladaron a la realidad local, regional, donde los liberales, representaban a los marginales y excluidos, mientras los conservadores movían la "Regeneración". Una cultura de la intolerancia, basada en la religión y la educación. Puntos fronterizos de los dos partidos.

La historia habla por sí sola de hechos refrendadores de lo dicho, dando noticia de la primera intemperancia personal que se traduce en la iteración de un ejercicio de fuerza, ayuno de referentes sociales en detrimento de la esperanza de la construcción de identidad nacional. Las siguientes citas validan cada contexto descrito y analizado.

El inicial intento para superar aquello surgió con el "Olimpo radical", fundamentado "en la ampliación de la ciudadanía incluyendo el pueblo, crear nuevas libertades y crear la legitimidad política, por fuera de la moral católica":

"En la ampliación de la ciudadanía incluyendo al pueblo, crear nuevas libertades y crear la legitimidad política por fuera de la moral católica, la visión de la nación de los liberales estaba relacionada con el progreso económico europeo o estadounidense y una sociedad laica formada por ciudadanos"1.

Proyecto liberal radical, cuya duración data de 1863, con Tomás Cipriano de Mosquera a 1878, con Julián Trujillo. Período caracterizado por el recrudecimiento del conflicto partidista evidente en una nueva colonización por vía del desplazamiento en el sentido de que los hacendados, buscando evitar aquella, se vieron compelidos a acaparar la tierra concentrándose la población en la cordillera oriental y central, conllevando a los colonos a escudriñar otros territorios, lo que motivó enfrentamientos entre hacendado, colono, arrendador y peones. Hecho evidente de la incapacidad del Estado para solucionar el conflicto e integrar territorios a la nación. Igual que en la colonia, con el agravante que en esta ocasión, por las circunstancias particulares, grandes porciones de tierra, les fueron adjudicadas a grandes propietarios y sectores productivos del país, quienes establecieron sus propios estatutos de regulación social para Estados.

La reseña a lo relatado aparece con el movimiento ultraconservador de la "Regeneración" que copó la historia desde 1878, con Julián Trujillo -paradójicamente, mandatario también en 1870 en plena vigencia del radicalismo- hasta su consolidación en 1886, con la Constitución Política de Núñez. Nacimiento de la hegemonía conservadora que perece con la intromisión directa en el poder de los liberales en 1930.

1 URREGO, Miguel Ángel. La crisis del Estado Nacional en Colombia. Morelia: Universidad Michocaria, 2004. P. 319 
En la Regeneración es notorio el intento por el retorno al esquema colonial, propiamente dicho. La consideración a los liberales como impíos, pecadores, sin alma, lo mismo que los indígenas para Gines de Sepúlveda - y el paradigma del ciudadano virtuoso, heredero de la cultura española en religión, lengua y cultura, son sus más claras expresiones. Presupuesto de violencia visible a través de los términos de exterminio con que pasó la historia este ciclo. La negación absoluta de las doctrinas liberales y socialistas, persecución a la masonería y la exclusión al diferente, sin fórmula de juicio alguna. Igual que ahora, valores tradicionales, insisto, provenientes de la colonia como improntas simbólicas del sagrado corazón con fines políticos, la estatización de creencias religiosas sin convicción por falta de juicio de gente, el escudo, el himno, la intolerancia religiosa y política, elementos que atan, sin duda, una sociedad inalterablemente colonial.

Véase entonces cómo esta parte de la historia de Colombia es una estructura de Estado colonial. La implementación de proyectos autoritarios, transgresión del derecho a la igualdad, política del exterminio, con el supuesto deseo de establecimiento del orden y la unidad, pero con resultados opuestos: hegemonía, autoritarismo y exclusión. Política de orden paternalista, con fetichismo religioso como factor instrumental del gobernante para dominar con facilidad a los sumisos irredentos y pacatos. Alejamiento de las prácticas conservadoras de las verdaderas necesidades del pueblo colombiano.

A este respecto nuestro profesor Leonardo Tovar escribe, refiriéndose al período comprendido entre 1922-1930:

"El desgaste del régimen conservador era evidente, pero todavía no era segura su caída. Después de medio siglo de dominio, el país se había acostumbrado a ello como algo natural, e incluso algunos liberales preferían la preservación del estatus quo, ante los intentos de socializar a su partido. Pero, sobre todo el clero continuaba controlando la opinión de la mayoría de la población, lo cual hacia prácticamente imposible el triunfo de un candidato liberal. De otro lado, sin embargo, la crisis había tocado fondo, y la ineficacia y corrupción del régimen era denunciado incluso por dirigentes conservadores, como Laureano Gómez. El golpe de decisión necesario para desencadenar el fin de la hegemonía conservadora fue obra de Alfonso López Pumarejo, quien en la convención liberal de 1929, en Bogotá, proclamó que el liberalismo debía preparase para reasumir el poder. Después de un proceso electoral, marcado por la falta de definición de los jerarcas de la iglesia, sobre el candidato conservador al cual debía apoyarse, triunfó el candidato liberal de transición Enrique Olaya Herrera, La República conservadora había concluido, pero cabría preguntarse hasta que punto su influencia ideológica no ha continuado presente en gran parte de nuestra mentalidad"?.

De cara a tan sombría experiencia aparecen abanderados democráticos populares, como el general Uribe Uribe, combatiente de la guerra de los Mil Días, liberal asesinado por los conservadores en 1914. Otra fue María Cano, defensora de la mujer, contradictora de la élite masculina.

2 TOVAR GONZÁLEZ Leonardo y otros. La filosofía en Colombia. Op. Cit. p. 314. 
La "revolución en marcha", inicio de la hegemonía liberal patentizada desde 1930 , con Enrique Olaya Herrera, hasta 1946, con Alberto Lleras Camargo, encontró en Alfonso López Pumarejo, padre del luego presidente Alfonso López Michelsen, durante el frente nacional, su mejor exponente de 1934 a 1938. Proyecto político opositor de la centralización autoritaria del régimen conservador que no obstante se convirtió en madre del clientelismo, producto de la reforma tributaria que en últimas favoreció los intereses particulares de industriales y cafeteros.

Así las ideas del caudillo, Jorge Eliécer Gaitan, en contra de la oligarquía son muestra diáfana del nuevo capítulo repetidor de la historia, en momento de enfrentamiento entre el país nacional, contra el país político. A extremo de considerarse el orador. "yo soy un pueblo", frase nada extraña en este siglo, en el que instrumentalizado el pueblo se le ficha como vocero de "Dios"; pero no con el propósito de crear unidad nacional, sino refrigeración del divisionismo y polarización que ha caracterizado a Colombia, desde la colonia, tal como lo venimos enseñando tras dar lectura a la realidad de los hechos.

Un escenario ampliado en número de personajes, tinglados en guerra fraticida (mujeres, niños) con más odios y la aparición de grupos de fuerzas privadas como los "chulavitas", originarios de Boyacá, y "los pájaros", sicarios contratados por el conservatismo para fulminar a los liberales en el campo. Lo que en los últimos años hicieron los paramilitares, los pepes, etc. Y ahora el grupo emergente conocido como las "Águilas Negras". Aún mas recientemente las mal llamadas "Bacrim".

Secuelas de la época colonial, forjadores de una violencia primaria que quiso solucionarse a palazos de ciego, pues con el Frente Nacional, seguido al derrocamiento del dictador Gustavo Porras Pinilla, se pensó en la tesis de que con la alternatividad en el poder, saciados los instintos quedarían, pero no, porque se siguió guardando la línea actitudinal, la negación de la verdad.

Nuevos conflictos de la colonización, contenidos en la redefinición del uso de la tierra. Por eso, el problema se agravó con el nuevo mito del Frente Nacional, repartiéndose los puestos de la burocracia; legitimación e institucionalización de la exclusión y la sustracción de la participación de la sociedad civil, en los diferentes procesos, lo que de suyo fertilizó el tercero de los mitos. El de la corrupción en todos sus ámbitos, política administrativa, educacional, judicial, etc.

Tal "organización" dio pie a los movimientos de resistencia, fragmentándose más la nación, no en masas subculturas, sino contraculturas. Casos como el del "bandolerismo social", personajes como Guadalupe Salcedo, Efraín González, Sangrenegra, Camilo Torres, son ejemplos.

En la misma tónica, históricamente emergieron los grupos M-19, FARC, EPL y el ELN con el ideario liberador de regiones, queriéndose separar del Estado.

De esta forma el descontento crece, la intolerancia es la norma y otra vez fallidos por la misma razón los intentos de pacificación dado que sectores otrora reaccionarios, cuando quisieron reconducir la marcha, resultaron exterminados por las fuerzas herederas de la colonia con su nota característica de que pensar distinto es ser enemigo para la conservación autoritaria del poder. Recuérdese al efecto el genocidio en contra de la Unión Patriótica, el homicidio del dirigente Luis Carlos Galán y muchos 
de sus colaboradores por haber tenido acento en la prosa y fuerza en el carácter, de denunciar la residencia de las nuevas formas del delito, mafia del narcotráfico, las camarillas, los inmorales de lo público, los ladrones de las instituciones, etc. Formas delictivas inmiscuidas en la política. Esto explica el fracaso de las investigaciones judiciales en casos como estos.

Por contera, la sociedad cerrada, excluyente, jerarquizada, idolatra, mezquina, fragmentaria, desigual y vulneradora sistemática de los derechos heredados de la Constitución de 1886 y por esta de la Colonia, se ve crecida monstruosamente por el paramilitarismo, el narcotráfico, los grupos guerrilleros, la delincuencia común, la mafia organizada, la corrupción consentida, por lo que recordamos; se precisó la necesidad inaplazable y urgente de un nuevo texto constitucional "capaz" de corregir los errores cometidos en el pretérito.

Sin embargo temprano decayó otra vez la ilusión, de un lado porque literación de la historial conocedores del juego de la democracia a su favor, la vieja política tradicional (heredera colonial) mostró su mayoría en los poderes regionales y locales, quedando por fuera, como ha sido costumbre, las minorías políticas y, de otro, porque así no se acepte prima facie por las últimas cabriolas como se pretende el puro autoritarismo presidencial; al presidente se le otorgaron constitucionalmente facultades de suyo dolencias de un auténtico Estado social de derecho. Las que pueden otearse en el nombramiento político de funcionarios de la rama judicial: el fiscal, por ejemplo.

La verdad es que en la Constitución del 91, si algo de hermenéutica y filosofía del lenguaje se aplica, resulta incontrovertible una modernización sin modernidad, un acto sin gracia y sobre todo una ruta sin camino, pues el modelo neoliberal allí plasmado no es más que la propuesta de reforma constitucional presentada por el señor César Gaviria, personaje cuyo nombre jamás olvidará la reseña de la historia, amén a su nombramiento en un cementerio, por palabras del hijo víctima de quien con serenidad dejó correr el telón que delató el panorama de una corrupción cada día más letal a cualquier propósito social o colectivo -1989-.

Un cúmulo de derechos fundamentales, finalmente violados por los mismos dirigentes herederos de la colonia. Una doble moral superada por la multimoralidad, sin esfuerzo mínimo de los dirigentes para auscultar su instinto perverso en términos del ejercicio del poder como práctica cotidiana. Contrario al llamado de la literatura constitucional en la necesidad de la protección de los derechos fundamentales, las consecuencias del particularismo no ideológico han venido aumentando como también las necesidades, la pobreza y la miseria.

"La población Colombiana está caracterizada por un particularismo no ideológico que restringe sus intereses en la política, solo aquellos aspectos que se relacionan con la vida personal privada o la familia. Este particularismo no ideológico ha sido relacionado con las relaciones anormales del sur de Italia. Estas similitudes con Sicilia: predominó de relaciones familiares, desconfianza entre personas, la mayoría de población participa en organizaciones religiosas, la poca existencia de organizaciones cívicas, políticas y deportivas entre otras, reflejan la larga ausencia de participación de la sociedad en la política municipal, regional y nacional, originando la abundancia del crimen, la violencia 
y la carencia de la ley; estas características clasifican a la sociedad colombiana en una zona de penumbras donde los individuos solo confían en sus familias, con evidente amoralidad, deterioro de la comunidad y una individualización intermitente" 3 .

Un Estado integralmente filtrado por las nuevas empresas criminales especializadas, a través de la historia con base en la conservación de los principios que dieron pie a una sociedad jerarquizada, excluyente, exterminadora, fetichista, sectaria, sinónimo de selectiva, autocrática, rudimentaria, primitiva, endogámica, plutocrática.

Una cultura política cargada con el "mito de la repetición". Con razón en su momento, la ideología conservadora de Miguel Antonio Caro -presidente de 1892 a 1898- "refleja la presencia de España en la cultura colombiana, manifestada en las costumbres jurídicas, en la lengua y sobre todo en la religión. Elemento sine qua non de nuestra vida civilizada". ${ }^{4}$

Nuestra historia desde la conquista hasta nuestros días es la historia de un mismo pueblo y una misma civilización. La cultura religiosa y civilización material, eso fue lo que establecieron los conquistadores, lo que nos legaron nuestros padres, lo que constituye nuestra herencia nacional, que puede ser conmovida, pero no destruida, por revoluciones políticas que fueron una transformación social.

\section{B. CONSTITUCIONALISMO COLOMBIANO, FRENTE AL RECURSO DE CASACIÓN DECLARATORIA DE NULIDADES DE CIERTOS FALLOS}

Como se sostuvo en el acápite anterior, retomando palabras de Roberto J. Salazar Ramos, seguido a una revolución, su fundamentación es esencial. En el caso nuestro, su fundamentación fue la república misma. El aparente paso de las armas, del triunfo militar que negándose a sí mismo como alternativa futura, suponía el más lúcido ejercicio del pensamiento para poner en términos de orden y progreso -la teoría de la modernidad de entonces- la nueva República. En otras palabras el ¿por qué? y el ¿para qué? de la revolución.

Es en este contexto en el que ubicamos la casación como la forma especializada con que un Tribunal de idéntica naturaleza puede revocar los fallos provenientes de las instancias tradicionales. Es el recurso parido por la Revolución Francesa en 1789, por medio del cual se pretendió ponerles coto a los abusos del monarca -lex regia-.

Se nos ha enseñado que una de las causas de la emancipación fue esta revuelta:

"Con Antonio Nariño y Camilo Torres, directamente influenciados por las ideas de la ilustración francesa y por el pensamiento de los próceres de la emancipación de las colonias inglesas de América del Norte, la ilustración neogranadina adquiere una dimensión política. La publicación de los derechos del hombre y su defensa por parte de don Antonio Nariño y el Memorial de agravios de Camilo Torres en víspera

3 REYES BELTRÁN, Pablo Ignacio. El mito en Latinoamérica y Colombia. Una mirada hermenéutica a la cultura política en Latinoamérica y Colombia. Colombia: Ibáñez, 2008. P. 216

4 TOVAR GONZÁLEZ, Leonardo y otros. La Filosofía en Colombia, Op. Cít. P. 322 
de la independencia representan dos piezas claves del pensamiento político ilustrado. Aunque es verdad, como lo afirma Gerardo Molina, que dichos planteamientos, solo son radicalizados a partir de la emancipación, siendo bajos estos aspectos el siglo "el siglo XIX nuestro siglo de las luces" 5 .

Si asumimos que ello fue así, no cabe duda de que en realidad como lo plantea Joaquín Zabalza Iriarte, O.P. La filosofía colonial énuestra tardía edad media?, pone de manifiesto en el basculamiento del pensar la diferencia entre el espacio y el tiempo, los términos análogos con su analogado principal”.

"Participan, por consiguiente, en alguna medida de la univocidad y de la equivocidad, dos extremos entre los cuales se sitúa bascula el pensar analógico. Se comparan, pues dos edades distintas y distantes en el espacio y en el tiempo, pero que tienen algo en común y que, por lo mismo, llamamos edad media, los adjetivos "nuestra" y "tardía, dicen relación a un espacio geográfico y a un tiempo histórico que no coinciden con los del analogado principal pero que, por dependencia histórica, participan de ciertos caracteres de la edad media sin más. El pensar analógico es legítimo; más aún puede ser un método conveniente de comprensión del devenir histórico, siempre y cuando no se caiga en simplificaciones de tipo univocista que borren las diferencias" 6 .

En efecto esos años que transcurrieron en Francia, comprendidos de 1789 -estallido de la Revolución por los sucesos en La Bastilla- a 1814 -el Congreso de Viena, tras la derrota de Napoleón- dieron vuelta al absolutismo, dejaron ver en su internodio la Asamblea Nacional con sus logros de supresión de los privilegios señoriales, la aprobación de la Declaración de los Derechos y la aprobación de una Constitución garante de la división de los poderes entre el rey, una asamblea legislativa, y los jueces; la asamblea legislativa de 1791 y la convención de 1792 que terminó con el golpe de Estado de Bonaparte en 1799. Luego se proclamó cónsul vitalicio y en 1804 se coronó emperador con el nombre de Napoleón I. El imperio perduró diez años y con la derrota de Waterloo es deportado a la isla de Santa Elena.

Es quizá lo que destaca lo acontecido en Colombia muchos años después de lo experimentado por Francia. Un amanecer tardío que por no haberse hecho las previsiones necesarias, la propia independencia terminó confundiéndose en sí misma por su trágica ambigüedad.

Así en el tema central de nuestro estudio encontramos que uno de los caminos nuevos para superar los de herradura consistió en el de la administración de justicia. Punto en el que si bien autorizados casacionistas, como nuestro colega y amigo el Doctor Armando Tolosa Villabona, advierten que antes de la Constitución de 1886, textos constitucionales refirieron a la casación en el sentido de autorizar a un Tribunal Supremo para tramitarlo con fines de declaratoria de nulidades de ciertos fallos, nuestra postura al respecto es un tanto diversa.

5 MOLINA, Gerardo. Las ideas liberales en Colombia, Bogotá: Tercer Mundo, 1971. P. 20

6 ZABALZA IRIARTE, Joaquín y otros, La Filosofía en Colombia, Op. Cit. P. 107 
En primer lugar porque la casación no es una mera nulidad -menos ahora- y en segundo lugar porque la competencia dada a un Tribunal especializado para tal efecto desprende de su propia naturaleza y no de la simple liberalidad o voluntad de un legislador o de un dictador, si se quiere. Además no se puede perder de vista el buen número de años que separaron a nuestro recurso extraordinario con estirpe constitucional (1886) con respecto a Francia, país en el que seguido a la Revolución (1789) "mediante el Decreto 27 de Noviembre de 1790, suprimió el consejo de las partes 'Conseil des parties' y otorgó funciones específicas a un Tribunal de Casación"7. Tal como lo dice el profesor Rafael Sandoval López, en su libro Recurso Extraordinario de Casación Penal.

\section{CASACIÓN MODERNA: TRASCENDENCIA HISTÓRICA EN LA DEFENSA O PROTECCIÓN DE LAS GARANTÍAS FUNDAMENTALES}

Con estas palabras empieza Tito Livio su relato sobre la historia de Roma:

"No sé a ciencia cierta si vale la pena relatar la historia de Roma, desde sus comienzos; pero, aunque lo supiera, no me atrevería a intentarlo, puesto que me parece un asunto viejo y ya manoseado, toda vez que constantemente surgen nuevos historiadores que pretenden, unos aportar a los hechos documentación más solida y otros sobrepujar con galas literarias la sencilla rudeza de los antiguos"8

Sin embargo, bien se sabe hoy en día cómo el desarrollo de las ciencias auxiliares de la historia, entre ellas la lingüística, la etnografía y la arqueología que se patentizan en la filosofía analítica, la hermenéutica y la fenomenología, permiten la aplicación de un método crítico a los relatos tradicionales para separar adecuadamente los mitos y las fantasías de las circunstancias objetivas. Ruta ésta la acertada de cara al descubrimiento no solo del pasado sino también de la actualidad de la casación como parte de la historia de Colombia en una de sus principales aristas de poder: la administración de justicia. Instituto del que no cabe la menor duda se erige la explicación de su origen en nuestro medio no tanto en una razón universal del derecho. Más bien como acción inmediata del uso del poder según convicciones personales de los mandatarios de turno o protagonistas de la misma historia. Acto reflejo del destino de los pueblos, escogido por algunos vinculando a los demás como colectividad, las más de las veces afectando su convicción general por la misma fuerza impetuosa de la imposición de las voluntades individuales. El conocido espíritu del pueblo desarrollado como escuela del derecho por Savigny.

Expresión de voluntad individual o particular manifiesta como resultado de la mezcla de distintos factores, en especial los de índole sentimental dependiente en gran medida de las creencias políticas, económicas y religiosas o de creencia espiritual.

En la Constitución cundinamarquesa en 1811, la facultad interpretativa de la Ley, no corresponde al poder judicial, cuando esa facultad en el artículo 20 del Título VI es función propia del poder legislativo: "El poder ejecutivo y el judicial deberán seguirlas a la letra (las leyes] y en caso de duda consultar al cuerpo legislativo", más

7 SANDOVAL LÓPEZ, Rafael. Recurso Extraordinario de Casación Penal. Bogotá: Ibáñez, 2008. P. 17.

8 TITO LIVIO. La monarquía romana. Víctor José Herrero Llorente (trad.). Madrid: Aguilar, 1969. P. 41 
en el Título VII, referente a las disposiciones del poder judicial, incluye un "Senado", como el Tribunal, en la cúspide de la administración de justicia con la tarea de "velar sobre el cumplimiento exacto de esta Constitución e impedir que se atropellen los derechos imprescriptibles del pueblo y del ciudadano". Aparentemente consagra uno de los fines de la Casación moderna, el de la defensa o protección de las garantías fundamentales, pero, ojo, en cabeza de un poder distinto al judicial.

La Constitución provincial de Tunja fija recursos de apelación y de súplica contra las sentencias ilegales, que se surtían ante el alto Tribunal de Justicia.

Así el pensamiento de Simón Bolívar presente en sus discursos y mensajes, como en las iniciativas constitucionales, va vislumbrando su opinión sobre la necesidad de plasmar el recurso. Sus planteamientos de política judicial permiten colegir un deseo por crear un control a las decisiones de los jueces en las instancias, dentro de las funciones de una Alta Corte.

Lo anterior sin incurrir en errores de interpretación pues si hubo predilección en el libertador por la lectura de filósofos franceses, ello no fue el rasgo concluyente de sus ideas, en la medida en que esos textos también eran compartidos por muchos de sus adversarios políticos. Bolívar siempre asumió una postura estratégica. Veamos.

Desde los inicios de la República, después del triunfo de la Batalla de Boyacá, se consolidaron las relaciones entre el Estado y la Iglesia. No se olvide el acta de independencia del 20 de julio de 1810, dieciséis de los cincuenta y tres firmantes eran clérigos:

"El gobernador del arzobispado, Juan B. Pey; el provincial del los agustinos, José Chavarría; el superior de Santo Domingo, Mariano Garnica; el guardián de San Francisco, Antonio González, el cura de la Catedral, Nicolás Mauricio de Omaña; el cura de las Nieves, Santiago Torres y Peña; el cura de Choachí, José Ignacio Pescador; el cura de La Mesa, Francisco Serrano Gómez; el cura de la Catedral, Pablo Plata; el capellán de La Peña, José Ignacio Álvarez; el rector de Nuestra Señora del Rosario, Antonio Gallardo; el cura de San Victorino, Vicente de la Rocha; el vicerrector de San Bartolomé, José Antonio Amaya; el cura de Anapoima, Juan Nepomuceno Azuero Plata; el cura de Ramiriquí, Julián Joaquín de la Rocha y el canónigo de la iglesia metropolitana Nicolás Cuervo"?.

Con la ley fundamental de la República de Colombia, sancionada el 17 de diciembre de 1819, el artículo 13 dispuso la proclamación de la nueva nación el 25 de diciembre:

"En celeridad del nacimiento del Salvador del Mundo, bajo cuyo patrocinio se ha logrado esta deseada unión, por la cual se regenera el Estado.

El preámbulo de la primera constitución de la República, proclamada en la Villa del Rosario de Cúcuta en 1821, manifiesta: "En el nombre de Dios, autor y legislador del Universo" 10 .

9 Gran Enciclopedia de Colombia - Instituciones 2, Colombia: El Tiempo, 2007. P. 59.

10 Gran Enciclopedia de Colombia. Op. Cit. P. 62. 
En la Constitución de Cúcuta de 1821, hay una extensa ley de organización judicial, expedida en la Villa del Rosario de Cúcuta el 12 de octubre de 1821, siendo presidente del Congreso José Ignacio de Márquez y Vicepresidente de la República, Francisco de Paula Santander. Ley conocida como Ley 14 de octubre de 1821 sobre organización de Tribunales y juzgados, distingue la Alta Corte de Justicia (con jurisdicción en toda la zona geográfica conocida como la Gran Colombia); la totalidad de la jurisdicción se divide en tres Distritos Judiciales: El primero, el norte, para Venezuela, Orinoco y Zulia; el segundo Distrito Judicial, del centro, para Magdalena, Cundinamarca y Boyacá; y el tercero, del sur, para el Cauca y la provincia de Quito. En cada uno de estos distritos se crea una Corte Superior de Justicia, con sedes en Caracas, Bogotá y Quito. Esta ley crea un recurso de nulidad contra las sentencias que resuelve tanto la Alta Corte de Justicia, como las tres Cortes Superiores de Justicia de los tres Distritos ${ }^{11}$.

El artículo 1 de la citada Ley, al organizar la Alta Corte de Justicia, fija como una de sus atribuciones la de "Conocer de los recursos de nulidad que se interpongan contra las sentencias dadas en las de revista, para el preciso efecto de reponer el proceso, devolviéndole, y hacer efectiva la responsabilidad", recurso éste que se interponía dentro de los cinco días siguientes a la notificación del fallo. En el artículo 11 numeral 9 igualmente se consagra este recurso, con competencia para las Cortes Superiores de cada uno de los tres distritos judiciales. Esta nulidad aquí procede frente a las sentencias proferidas por los tribunales y juzgados inferiores en las causas en que no tenía lugar la apelación. En este trámite del recurso a el efecto opera el efecto devolutivo, es decir, que la sentencia recurrida se cumplía, de conformidad con el artículo 27 de la misma ley, pero la interposición del recurso de nulidad, "no impedirá que se lleve a efecto desde luego la sentencia ejecutoriada, dándose por la parte que la hubiere obtenido la correspondiente fianza de estar a las resultas, si se mandare reponer el proceso".

Luego el proyecto de Constitución que Simón Bolívar presentó a consideración del Congreso Constituyente de las provincias del Alto Perú, conocida hoy como República Boliviana, y enviada al Congreso el 25 de mayo de 1826, resultó aprobado en julio de 1826. En el artículo 105, como atribuciones del Tribunal Supremo de Justicia, en el ordinal VIII: "Oír las dudas de los demás tribunales sobre la inteligencia de alguna ley; y consultar al Ejecutivo para que promueva la conveniente declaración en las cámaras", y el ordinal IX: "Conocer de los recursos de nulidad que se interpongan contra las sentencias dadas en última instancia por las Cortes de Justicia".

Este proyecto incluye los fines públicos de la Casación tradicionalmente fijados por la doctrina y la jurisprudencia frente al derecho objetivo. Además plasma el recurso de nulidad contra sentencias, propuesto por el General Santander en la Ley 14 de octubre de 1821, que expidió el desarrollo de la Constitución de Cúcuta, siendo Vicepresidente. Aparece así otro punto, el de anular o quebrar un fallo. De otro lado, el proyecto del Libertador resalta el fin del cumplimiento del derecho objetivo

11 Para algunos si solo hasta 1886 encontramos una alusión expresa al recurso de casación, la atribución de conocer del recurso la encontramos en un conjunto normativo donde se desprenden funciones y fines del mismo, como atribución de la Corte de Justicia. Tolosa Villabona, Luis Armando: Teoría y Técnica de la Casación: Doctrina y Ley, Bogotá, 2005. P. 100-103. 
y de la unificación jurisprudencial. Aparece evidenciada la función nomofiláctica de la Casación. No sobra advertir que la Constitución de Bolívar quería ser modelo para los diferentes países de la región, obra de Bolívar. El Bolívar emancipador, ahora legislador. "La providencia y no mi heroísmo, han operado los prodigios que admiráis"1?.

En lo atinente a la permanente relativa tolerancia religiosa entre clericales y anticlericales, en 1828, el decreto orgánico de la dictadura de Bolívar estableció: "El gobierno sostendrá y protegerá la religión católica, apostólica, romana como la religión de los colombianos".

La Constitución de la República de Colombia de 1830, año en que murió el Libertador, consagró en el artículo 110 la existencia de una Alta Corte de Justicia, y consignó el fin nomofiláctico que hoy cumple la Casación. El numeral 4 expresó: "Conocer de los recursos que le atribuya la ley contra las sentencias de las Cortes de Apelación", y en el numeral 9 de esta Constitución señala como atribución de esta Alta Corte: "Oír las dudas de los tribunales superiores sobre la inteligencia de alguna ley, y consultar sobre ellas al Congreso por conducto del Poder Ejecutivo".

En cuanto a la religión, por iniciativa de Bolívar esta Constitución dedicó un título del siguiente tenor: "La religión católica, apostólica, romana es la religión de la República. Es un deber del gobierno, en ejercicio del patronato de la Iglesia colombiana, protegerla y no tolerar el culto público de ninguna otra"13.

En la Constitución de 1832, donde Colombia tomó el nombre de Nueva Granada, en el artículo 131 se habla del máximo Tribunal como Corte Suprema de Justicia, y en el numeral 6 se incluyó, como atribución de esta Corte, "Oír las dudas de los tribunales superiores sobre la inteligencia de alguna ley, y consultar sobre ellas al congreso por conducto del poder ejecutivo".

En este período se conservó la intolerancia por cualquier culto distinto al católico. La carta política expresó: "Es también deber del gobierno proteger a los granadinos en el ejercicio de la religión católica, apostólica y romana"14. A tiempo que la del 1843 señaló: "La religión Católica, apostólica, romana es la única cuyo culto sostiene y mantiene la República"15.

En la Constitución de 1858, Colombia toma el nombre de Confederación Granadina y no aparece consagrado expresamente el recurso de Casación, en el artículo 51 del texto se expresa: "La Corte Suprema oirá las consultas que le dirijan los jueces y tribunales de la Confederación sobre la inteligencia de las leyes nacionales, y las dirigirá al Congreso expresando su opinión sobre el modo de resolverlas".

Por lo tanto, este conjunto de textos constitucionales permite deducir que no aparece plasmado constitucionalmente el recurso de Casación como lo conocemos hoy, sí vislumbradas algunas de sus finalidades: función nomofiláctica del derecho objetivo y nulidad para el control de las sentencias.

12 Aparte del discurso pronunciado por el Libertador en la asamblea celebrada en el convento de Religiosos Franciscanos, el 2 de enero de 1814.

13 Gran Enciclopedia de Colombia. Instituciones 2. Op. Cit. P. 63.

14 Gran Enciclopedia de Colombia. Instituciones 2. Op. Cit. P. 63.

15 Gran Enciclopedia de Colombia. Op. Cit. P. 63. 
En periodo 1853 a 1886, cuando emergieron los Estados Soberanos, gracias a la creciente federalización de Colombia, primero en la Constitución de 1853, luego en la de 1858 y finalmente en la 1863, hubo una progresiva legislación interna y en muchos campos dualidad de legislaciones encontrando legislación en los Estados Soberanos y legislación de la Unión o Confederación; pero en esta época la atribución de la Corte de ejercer función nomofiláctica de derecho objetivo solo se plasma en la Constitución de 1858.

La Constitución de 1863 es la única en nuestra historia en no invocar el nombre de Dios en su preámbulo. Fue proclamada "en nombre y por autorización del pueblo y de los Estados Unidos Colombianos que representa" símbolo de la ruptura entre Iglesia y Estado.

Por ende, la tesis terminante de quienes opinamos que el Instituto de la Casación tiene su génesis en Colombia a partir de 1886 obedece en primer lugar a su mención específica, la atribución de competencia a la Corte Suprema de Justicia y sobre todo a la clara intención de mera legalidad del recurso, evidente en las causales, su procedencia y trámite. Consecuencia de una voluntad plasmada por el libertador de quien nadie puede sostener su ajenidad a los destinos de la patria. Punto que seguirá siendo tratado en el siguiente acápite.

\section{LA CONSTITUCIÓN DE 1886 Y LA EXPRESIÓN CONSTITUCIONAL DEL TÉRMINO CASACIÓN. PUNTO DE PARTIDA DEL RECURSO COMO SECUELA DEL PASADO}

Con la Constitución de 1886 se consagra constitucionalmente de forma expresa el término "Casación". El artículo 151 atribuyó a la Corte Suprema de Justicia la facultad de actuar como Tribunal de Casación, consignando, en el numeral 1, que es atribución de la Corte Suprema: "Conocer de los recursos de Casación, conforme a las leyes". Cosa similar ocurre en el siglo XX con la Constitución Colombiana de 1991, que insertó de forma parecida el recurso de Casación atribuyendo a la Corte Suprema de Justicia, en su artículo 235, la función de "actuar como tribunal de Casación".

Aspecto no casual sino causal con el cierre de más de 30 años de conflictos por el tema religioso y el Estado volvió a ser confesional:

“El preámbulo de la carta proclamada en 1886 decía "En el nombre de Dios, fuente suprema de toda autoridad", renovando así la invocación al Ser Supremo que había estado presente en todas las constituciones anteriores, con excepción de la de 1863.

En el artículo 38 de la constitución de 1886 marcó el fin de la ruptura entre el Estado y la Iglesia, así como el restablecimiento de las relaciones de colaboración y apoyo entre las dos potestades:

La religión católica, apostólica, romana, es la de la nación; los poderes públicos la protegerán y harán que sea respetada, como esencial elemento del orden social" 16 .

16 Gran Enciclopedia de Colombia. Instituciones 2. Op. Cit. P. 75. 
La constitucionalidad del recurso, entonces, se vierte en su naturaleza y en la serie de principios que lo ordenan. Entre otros los contenidos en el preámbulo en su momento defendido por Bolívar.

La Constitución que mantuviera su vigencia por más de un siglo, es decir, entre 1886 y 1991, resulta ser expresión de las ideas de Regeneración, fincadas en un Estado claramente centralista, dogmas de soberanía nacional y unidad del Estado.

En otras palabras en sus artículos se concibe una nación como República, en que la soberanía mora en la Nación, siendo fuente de los poderes públicos. Ello se expresa en un régimen centralizado donde los órganos locales exonerados de la función legislativa se reputaban de naturaleza administrativa siendo subordinados al control del Ejecutivo nacional.

Además el naciente régimen precipitó dividir administrativamente a la Colombia de hoy en aquel entonces en departamentos, provincias y distritos municipales. Denotando la constitución de 1886 la facultad del Presidente de la República de nombrar y remover de su cargo a los gobernadores, aunque no se pronunciaba respecto a la designación de los alcaldes, siendo clara en ser agente del gobernador, llevando a deducir que el ejecutivo de orden departamental era quien ostentaba tal atribución, en el entendido de ser un sistema jerarquizado y centralista.

Al revisar el texto constitucional de 1886 se observa que los órganos colegiados deliberantes están en la cabeza de un Concejo municipal y una Asamblea departamental con prerrogativas administrativas pero sin facultades legislativas.

Pero es de advertir que la ley 14 de 1887 fija un régimen de excepción permitiendo al Presidente integrar tales entes colectivos, siendo para él potestativo delegar tal atribución en el gobernador. Seguidamente la ley 149 de 1888, que se constituye en Código de régimen político y municipal, confirma el origen electivo de los Concejos municipales como de las Asambleas departamentales. Pero sí excluye la elección de los Ejecutivos locales, en otras palabras, el alcalde lo nombra el prefecto o jefe de la administración provincial quien fuera designado por el gobernador. En fin, lo dicho lleva a concluir la inexistencia de autonomía de los departamentos, al equipararse sus intereses con los de la nación.

Así las cosas, en 1908 se cambió tal régimen conllevando la eliminación de las provincias, que tienen nueva vigencia un año después, conforme el acto legislativo de fecha 29 de marzo de 1909.

En punto de las reformas a la constitución de 1886, se puntualiza en el acto legislativo 3 de 1910 en que el sistema de administración territorial acoge características actuales, "se restablece el voto popular y directo de los ciudadanos para la integración de las corporaciones administrativas departamentales y municipales"17, además en el artículo 62 hace del alcalde un agente del gobernador y a su vez jefe de la administración municipal. La reforma de 1936 afecta la división del territorio colombiano pues mantiene los departamentos en las regiones de mayor desarrollo, siendo las otras estructuradas como intendencias y comisarias, atendiendo al bajo nivel socioeconómico y su especial

17 Gran Enciclopedia de Colombia. Instituciones 2. Op. Cit. P. 25. 
tutela acogida por el gobierno central, por tanto, intendente y comisario eran designados por el Ejecutivo central, mientras los Concejos intendencial y comisarial eran votados por el cuerpo electoral, "el sistema de organización concebido sobre la base de un cuerpo colegiado de tipo electivo y un Ejecutivo unipersonal, se conserva tanto para los municipios como para los departamentos"18.

Para el año de 1945 se da otra reforma a la Constitución de 1886 no extraña al tema del territorio desde la perspectiva de su división, puesto que se tiene noticia que las intendencias y comisarías fueron divididas en municipios, destacándose para tal anualidad que Bogotá se organizó como Distrito Especial, sin subordinarlo al régimen municipal ordinario, dentro de los parámetros establecidos en la ley.

"El acto legislativo 2 de 1954 atribuyó al Presidente de la República y a la Asamblea Nacional Constituyente poderes conjuntos con el fin de designar a los miembros de los Consejos administrativos que debían cumplir las funciones antes correspondientes a las Asambleas departamentales. También los Concejos municipales desaparecieron, y se crearon cuerpos administrativos"19.

Se informa en referencia a lo dicho en el párrafo anterior que la selección de los miembros de estas corporaciones se tenía como una facultad del Presidente de la República como al Consejo administrativo departamental.

El plebiscito de 1957 sirvió para volver al esquema que regía anteriormente, es decir, el órgano ejecutivo escogido por el pertinente superior jerárquico, y corporaciones administrativas elegidas popularmente.

La reforma de 1968 mantuvo incólume las propiedades esenciales del sistema, por tanto, alcaldes y Concejos municipales siguieron vigentes.

"La reforma de 1986 implicó una ruptura del sistema rígidamente centralizado, introdujo la elección popular de alcaldes y previo la existencia de un sistema de democracia directa: la consulta popular. El alcalde dejó de ser agente del gobernador y conservó su investidura como jefe de la administración municipal"20. Entre tanto en los departamentos se conservó la designación del gobernador por el Presidente y la asamblea departamental resultaría conformada por elección popular.

Así no hay duda de la estirpe constitucional del recurso, tal como desde un principio aconteció en Francia. Cuenta ya con una historia constitucional, bien abigarrada. Por eso la Constitución Colombiana de 1991, después de detallar las acciones que tienen igual estirpe constitucional, como la acción de hábeas corpus, la acción de tutela, las acciones populares y de grupo y la acción de cumplimiento, en el artículo 89 enseña que "la ley establecerá los demás recursos, las acciones y los procedimientos necesarios para que puedan propugnar por la integridad del orden jurídico y por la protección de sus derechos individuales, de grupo o colectivos frente a la acción u omisión de las autoridades públicas". Y luego de introducir la acción especial de pérdida de investidura contra congresistas, le da cabida constitucional a la Casación.

18 Gran Enciclopedia de Colombia. Instituciones 2. Op. Cit. P. 25-26.

19 Gran Enciclopedia de Colombia. Instituciones 2. Op. Cit. P. 26.

20 Gran Enciclopedia de Colombia. Instituciones 2. Op. Cit. P. 26. 
En consecuencia el recurso de Casación es un recurso no solo de naturaleza legal, sino de talante constitucional; institución jurídica que ciertamente ha venido siendo modulada y humanizada por la Corte Suprema de Justicia con base en la Jurisprudencia de la Corte Constitucional.

Por lo tanto, desde la perspectiva constitucional se deduce que la Corte Constitucional es fundamentalmente un Tribunal de Constitucionalidad y la Corte Suprema de Justicia, un Tribunal de Casación y de legalidad frente a las sentencias de la jurisdicción ordinaria, una de cuyas funciones básicas consiste en la unificación de la jurisprudencia, cumpliendo los fines de la Casación en interés del derecho objetivo y del restablecimientos de los derechos subjetivos conculcados por los fallos.

De acuerdo con la Constitución vigente en Colombia, y al desarrollo jurisprudencial, corresponde a la Corte Suprema como Tribunal de Casación, en su atribución de Juez de Casación seguir, entre otras, las siguientes reglas. Ellas, aclaramos, legalmente diferentes a las de costumbre derivadas del Marco Colonial rediseñado en la Constitución de 1886:

1. La prevalencia del derecho sustancial sobre el derecho instrumental de que trata el artículo 228 de la C.N. El derecho sustancial no puede ser desconocido so pretexto de aplicar el derecho instrumental, de forma que el recurso de Casación no constituya un recurso marginal, elitista y formalista.

2. Asegurar el principio de igualdad.

3. La garantía como un todo del debido proceso de que trata el artículo 29 de la Constitución Nacional, para seguridad del Estado y de los ciudadanos, por cuanto debe garantizar la corrección material de la ley, la legalidad del juicio, el respeto de los derechos individuales y el mantenimiento de un orden jurídico justo, dentro del marco del Estado social de derecho.

4. La reparación de los agravios que sufran las personas dentro del proceso con ocasión de las sentencias en las que el juez incurre en errores in iudicando y errores in procedendo.

5. La justicia material como expresión de Libertad, en un Estado social de derecho.

6. La causal primera de Casación, como marco de acción de los sujetos.

7. El recurso de Casación busca garantizar un orden justo.

8. La causal de prohibición de reformatio in peius, plasmada en el artículo 31 de la Carta cuando dice: "que el superior no podrá agravar la pena impuesta cuando el condenado sea apelante único", aun cuando no aparezca hoy como causal autónoma de Casación en materia penal en el derecho colombiano, podrá alegarse por vía de causal primera en la Casación penal.

9. "In dubio pro reo" 21.

21 Las anteriores consideraciones son producto de la experiencia del autor como asesor, Procurador Delegado ante la Corte, magistrado auxiliar de la Corte Suprema de Justicia, abogado litigante, Decano de Facultad de Derecho de Universidad Pública, y profesor de posgrado de Teoría General de la Casación. 
Un auténtico juicio, lógico, técnico jurídico de la legalidad constitucional de la sentencia a diferencia de la simple labor revisoria de una técnica que por su orientación legalista, soslayaba derechos y garantías, tal como era nota característica de la colonia. Esquema dentro del cual galopaba la discriminación de los derechos entre los hombres.

Entonces fácil resulta concluir que las constituciones fueron brújula acompañante en la historia colombiana de su cultura política como de su cultura judicial, en tanto que la primera ha dado vida a la segunda, por contera derivada o heredera de los genes fenomenológicos de aquella.

Es evidente que la claridad irrogada alrededor dentro del marco constitucional de 1886 no fue algo distinto a la prédica de Núñez de su carácter de regenerador, conservador, hegemónico, con las notas conocidas y peculiares del periodo en que ese ciclo colmó nuestra historia, las cuales recordamos: sociedad dividida, polarizada, jerarquizada, trunca, excluyente, mentalizada puestera, endogámica, plutócrata, particularizada sin ideología. Las mismas notas de la colonia, que hicieron presa del dolor y la angustia al libertador al verse traicionado. Al respecto en su estudio "Tradicionalismo y Neoescolástica en Colombia", el profesor Leonardo Tovar, sobre la época en que surge con expreso rigor la casación, sintetiza:

"Las consecuencias de este proyecto en la Constitución de 1886 y en el Concordato de 1887 son bien conocidas, y como comenta el maestro Gerardo Molina, allí se encuentra la razón fundamental de la mentalidad conservadora del pueblo colombiano. Desde el punto de vista de la historia estricta, el Partido Nacional que formó Núñez con integrantes del conservatismo. Sin embargo, el Regenerador siempre reivindicó su condición de liberal y culpó a los dirigentes radicales de haber sido quienes lo habían abandonado, obligándolo de aliarse con la oposición. ¿Qué podemos pensar de todo esto? Sin entrar en controversias históricas sobre la asignación partidista de Núñez, podemos aceptar que se trataba de un liberal, pero desde luego no en el sentido laiseferiano anterior. Sus ideas políticas, sus ideas económicas, sus ideas religiosas introducen un nuevo sentido de liberalismo que a pesar de algunas resistencias anteriores, el país terminaría por acoger. Sin duda, Núñez se equivocó, sobre todo porque dejó trunca su labor y entró el poder a la reacción, pero ello no le quita el título de haber sido el verdadero fundador del estado-nación en Colombia"².

\section{CONCLUSIONES}

En punto de los resultados obtenidos en este trabajo de investigación, se insiste de corte netamente histórico descriptivo, se pueden sintetizar de la siguiente forma:

Sobre nuestra historia, no cabe la menor duda del carácter indispensable de que sea estudiada a partir de la totalidad de las fuentes de información, más allá de los fenómenos propiamente dichos, que le restan sustancia al conocimiento de lo verdaderamente acontecido. Tal es el caso aquí planteado en el que actualmente

२2 TOVAR GONZÁLEZ, Leonardo y otros, La filosofía en Colombia. Op. Cit. P. 318. 
diferente a tenerse certeza sobre las relaciones de los diversos factores que han propiciado nuestro presente, las dudas se han ido aparentemente diluyendo con base en relatos no coincidentes con lo que muestran las distintas épocas. En ese sentido la filosofía crítica juega un papel fundamental de cara a la construcción del Estado social de derecho proclamado en la Constitución de 1991. Trabajo de imposible realización si es que no se rompen esos paradigmas presentes a lo largo de los tiempos desde la conquista hasta nuestros días.

Tratándose de la supuesta coincidencia entre los personajes de la historia, esta alternativa sufre un vuelco para convertirse en causalidad demostrada a través de los aconteceres dentro de los que se movieron los sujetos y las distintas circunstancias que los rodearon, sin descartar sus impulsos, ambiciones, concepciones religiosas, éxitos, convicciones, fracasos. En fin, todo lo relacionado con la forma integral como los personajes enfrentan el mundo desde sus posiciones. La carta de Colón deja ver su visión real pero también ideal del mundo para con ello satisfacer sus deseos de conquista y reconocimiento en una época de las dos espadas. Mientras que con Bolívar en Jamaica, sus cartas en especial la firmada el 6 de septiembre de 1815 dirigida a Henry Cullen "Contestación de un americano meridional a un caballero de esta isla" describió la situación de América en su conjunto y algo de clarividencia a extremo que sus dichos se cumplieron a cabalidad a lo largo del siglo XIX.

No debemos buscar la existencia de la justicia en la legalidad de los fallos o en la ritualidad de la construcción de las leyes sino su presencia en la actitud valerosa de los jueces y los legisladores, que incluye la honestidad y la intelectualidad, no la alevosía ni la transgresión verificable en el abuso del poder.

La historia legal de la casación es la radiografía que muestra sin apasionamientos la presencia de la voluntad de Bolívar en la Constitución de 1886, lo que se abstuvo de hacer en vida material el Libertador, por estrategia para evitar los abusos del poder de sus antagonistas, quienes, desesperados ante la astucia del Presidente, también fracasaron en su intento de darle muerte. Hecho éste que invita a reflexionar si hacia el inmediato futuro, tendremos que esperar tantos años para producir cambios a sabiendas de su necesidad pero que por los personalismos todo sucumba en detrimento de la libertad y el progreso de los tiempos.

Temas de incesante discusión en la actualidad devienen de la misma premisa. Piénsese en el mal denominado "Choque de trenes", en la designación de Procurador General de la Nación, de Fiscal General, incluso la del primer mandatario.

Dentro de esta tónica resulta incuestionable que gran parte de nuestra jurisprudencia en la Sala Penal de la Corte Suprema de Justicia fue construida con base en la urgencia de la protección de la legalidad que en la misma necesidad de hacer compatible el derecho con la justicia.

Me confieso un hombre creyente y formado en la fe, dentro del credo agustiniano, pero no por ello invidente ante la realidad histórica del país. Por el contrario, al estilo de Agustín de Hipona, denunciante de los abusos del imperio romano en su obra acimut La ciudad de Dios, ahora y aquí testimoniamos las flaquezas y debilidades del sistema, apresto a concursar en la reingeniería de un pensamiento separado de las presiones que permita ejercer a plenitud la libertad con conciencia. Aquella arrasada en la conquista, entre otros factores con la denominación "del 
otro", ratificado en la colonia y lamentablemente incorporado por nuevas vías en la emancipación, corolario en la República y fastidio permanente en el Estado social de derecho.

En Colombia las ventajas obtenidas por el caudillismo, el gamonalismo, el partidismo siendo víctimas los destinatarios de la ley, llevan a realizar ejercicios adicionales de pensamiento centrado en el concierto universal de las cosas, del cual formamos parte los seres humanos. Desde esta perspectiva los factores disonantes con el pluralismo, la colectividad y el fin común, provenientes de la colonia, que separaron, dividieron, polarizaron, discriminaron y reprodujeron la violencia nacida en la conquista, deben desaparecer. Para ello el consenso, la participación, la oportunidad, la opción, la posibilidad. Una física cuántica aplicada a la sociedad colombiana, de tal manera que por los fallos no se aumenten las frustraciones ni los fracasos, mas bien que con ellos la ciudadanía sienta latente un mejor futuro, una confianza, una lealtad. Una verdadera ley que no por estar escrita vale, sino porque quien la aplica es prenda de garantía para los suyos y para los otros.

La iteración de la historia ha sido nuestra historia. Desconocer la historia es grave. Es eliminarnos, sustraernos, desaparecernos, es decir, darle gusto a los que pretendieron separarnos de la naturaleza a la que correspondemos. Una conquista de ofensa, por una de amor y comprensión, una colonia pero de justicia, una República pero de verdadera cosa pública como lo enseña su etimología. Descubrir que la emancipación no es cuestión de mera rebeldía sino de convicción enderezada al ejercicio de todos los derechos.

Resulta insólito en un país aparentemente orientado por las leyes que deje un abismo en la historia de su sistema jurídico por un tiempo tan prolongado (1910-1923). Lo que de suyo explica que en materia penal la casación se instrumentalizó únicamente con fines de reacción frente a los delitos que tenían prevista la aplicación de la pena capital. Quedando al desgaire la protección de los fines por cuya razón nació la casación en el movimiento revolucionario francés.

Demanda esfuerzos adicionales de intelectualidad limpia hechos tales como intentar comprender y entender la preexistencia de labores al interior de una misma corporación, que finalmente conculcan la lógica y la misma técnica como vino ocurriendo en extensos espacios de la historia al ser competente nuestra Corte Suprema de Justicia, del adelantamiento de únicas instancias y a la vez del recurso extraordinario de casación. En el primero de los casos aplicando un derecho susceptible de amplia interpretación, mientras que en el segundo de estrictez hermenéutica.

Cuando en la naturaleza humana como en los fenómenos jurídicos convertidos en institutos, hay revestimiento con factores distintos a los de sus propias esencias, tales artificialidades se elevan coligiéndose en principales elementos constitutivos de las injusticias a todo nivel. Sobre todo si echamos fruto con raíces ajenas. Lo cierto es que el territorio ha sido, es y será nuestro. Es cuestión de dignidad.

Bienaventurados los que enseñan con su vida, porque aquellos incapaces de hacerlo ni siquiera se dan cuenta de lo que han vivido.

Esa falta de demostrada unidad nacional visible en las tendencias grupistas y clasistas han desprovisto al Estado de verse inescindible en casos como el de la 
administración de justicia y para hablar de tiempos modernos, lo que explica el rechazo sin fundamento de la búsqueda por los propósitos comunes lempresa, universidad, Estado), a pesar de la propuesta constitucional del 91. Pervive el ensimismamiento en la recalcitrancia.

\section{BiBLiografía}

Alexy, Robert (1997). Teoría de la argumentación jurídica. Madrid: Prisma.

Molina, Gerardo (1971). Las ideas liberales en Colombia. Bogotá: Tercer Mundo.

Reyes Beltrán, Pablo Ignacio (2008). El mito en Latinoamérica y Colombia. Una mirada hermenéutica a la cultura política en Latinoamérica y Colombia. Colombia: Ibáñez.

Sandoval López, Rafael (2008). Recurso extraordinario de casación penal. Bogotá: lbáñez.

Tito Livio (1969). La monarquía romana (traducción de Víctor José Herrero Llorente). Madrid: Aguilar.

Tolosa Villabona, Luis Armando [2005). Teoría y técnica de la casación. Bogotá: Doctrina y Ley.

Urrego, Miguel Ángel [2004). La crisis del Estado nacional en Colombia. Morelia: Universidad Michocaria.

Varios Autores (2007). Gran Enciclopedia de Colombia. Instituciones 2. Bogotá: Círculo de Lectores.

Zabalza Iriarte, Joaquín et ál. La filosofía en Colombia. 